\title{
Yabancı Dil Olarak Türkçe Öğrenen Uluslararası Öğrencilerin Motivasyon Durumları ${ }^{1}$
}

\author{
Şirin Kübra YAĞMUR \\ Öğr. Gör., Ankara Medipol Üniversitesi, \\ Yabancı Diller Yüksekokulu \\ yagmursirinkubra@gmail.com \\ Orcid ID: https://orcid.org/0000-0002-9052-3192
}

\begin{abstract}
Öz
Bu çalışmanın temel amacı, yabancı dil olarak Türkçe öğrenen uluslararası öğrencilerin dil öğrenme konusundaki motivasyon durumlarını belirleyebilmek için motivasyon ölçeğini yabancı dil olarak Türkçe öğrenen uluslararası öğrencilere uygulamaktır. Öğrencilerin motivasyon durumları yaş, uyruk ve dil seviyelerine göre değerlendirilecektir. Araştırmada Sevim (2019) tarafından geliştirilen, toplam üç boyuttan (içsel, araçsal ve kültürel) ve 22 maddeden oluşan "Yabanc1 Dil Olarak Türkçe Öğrenmeye Yönelik Motivasyon" ölçeği uygulanmıştır. Ölçek, yabancı dil olarak Türkçe öğrenimi alanında motivasyona ilişkin ilk örnek olması sebebiyle önem taşımaktadır. Yapılan araştırmaya Türkiye'de bulunan toplam 103 öğrenci dâhil olmuştur. Çalışma kapsamında Ankara Medipol Üniversitesi Türkçe Hazırlık Okulu'nda öğrenim gören 46 öğrenci, Kahramanmaraş Sütçü İmam Üniversitesi Türkçe Öğretim Merkezi'nde öğrenim gören 40 öğrenci ve Yedi Kita Uluslararası Öğrenci Derneği'ne üye olan 17 öğrenciden veri toplanmıştır. Araştırmanın verileri, SPSS 24.0 ile analiz edilmiştir. Sonuçlara göre, araçsal motivasyon, ülkeye göre anlamlı farklılık göstermektedir $(\mathrm{p}<0,05)$ ve İranlı öğrencilerin araçsal motivasyon puanları diğerlerine göre daha yüksek çıkmıştır. Öğrencilerin içsel ve kültürel motivasyonlarına bakıldığında, yaş ve dil seviyeleri açısından anlamlı bir farklılık olmadığı ortaya çıkmıştır. Puanlar arasındaki fark istatistiksel olarak anlamlı bulunmasa da, puan ortalamalarında bir fark görülmektedir. Katılımcıların ülkelerine, yaşlarına ve dil seviyelerine göre kültürel motivasyon puan ortalamaları düşük çıkmıştır. Toplam puan ortalamalarına göre ise, yabancı dil olarak Türkçe öğrenmeye yönelik motivasyonun tüm değişkenlere göre yüksek olduğu görülmüsşür.
\end{abstract}

\footnotetext{
${ }^{1}$ Makale Geliş/Kabul Tarihi: 27.09.2021 / 22.12.2021

Künye Bilgisi: Yağmur, Ş. K. (2021). Yabancı dil olarak Türkçe öğrenen uluslararası öğrencilerin motivasyon durumları. Kahramanmaraş Sütçü Imam Üniversitesi Sosyal Bilimler Dergisi, 18 (3), 1628-1639. DOI: 10.33437/ksusbd.1001250
} 
Anahtar Kelimeler: Motivasyon, Yabancı Dil Olarak Türkçe Öğrenimi, Yabanc1 Dil Motivasyonu.

\title{
Motivation Status of International Students Learning Turkish as a Foreign Language
}

\begin{abstract}
The main objective of this study is to apply the motivation scale to international students learning Turkish as a foreign language in order to determine the motivation status of international students learning Turkish as a foreign language. Motivation status of students will be evaluated by their ages, nationalities and language levels. In the study, the scale of "Motivation Towards Learning Turkish as a Foreign Language”, developed by Sevim (2019), consisting of a total three dimensions (internal, instrumental and cultural) and 22 items, was applied. Scale carries importance as it is the first example regarding motivation in the field of learning Turkish as a foreign language. A total of 103 students in Turkey were involved in the research. Within the scope of the study, data were collected from 46 students studying at Ankara Medipol University Turkish Preparatory School, 40 students studying at Kahramanmaraş Sütçü İmam University Turkish Teaching Center and 17 students who are members of the Yedi Kita International Student Association. Data from the research were analysed with SPSS 24.0. According to the results, instrumental motivation differs significantly by country $(p<0,05)$ and the instrumental motivation scores of Iranian students were higher than the others. When the internal and cultural motivations of the students were examined, it was revealed that there was no significant difference in terms of age and language levels. Although the difference between the scores is not found statistically significant, a difference is seen in the score averages. According to participants' countries, ages and language levels, the cultural motivation score averages were low. According to the total score averages, it was seen that the motivation towards learning Turkish as a foreing language was higher than all the variables.
\end{abstract}

Keywords: Foreign Language Motivation. Learning Turkish as a Foreign Language, Motivation.

\section{GİRIŞ}

Günümüzde yeni bir çağa ayak uydurmanın, yenileşmeye ve değişime yetişebilmenin olanaklı duruma gelebilmesi için iletişimin göz ardı edilmemesi gerektiği bilinmektedir. İletişim, ülkelerin siyasi ilişkilerinde, eğitim 
politikalarında, turizm faaliyetlerinde her zaman ön plandadır. Ülkeler arası ilişkilerin sürdürülmesinde kullanılan temel araç dildir. Milletler politik, siyasi, ekonomik sebeplerle birbirlerine bağlı duruma gelmiştir.

Bireyler, çeşitli olanaklardan yararlanma düşüncesi, eğitim alabilme isteği ya da kendi ülkelerindeki ekonomik ve politik sıkıntılardan uzaklaşma arzusuyla farklı bir ülkeye gitmektedir. Farklı amaçlarla gidilen ülkelerin dilini öğrenmek kaçınılmaz olmuştur. Kimi zaman kendi isteğiyle dil öğrenen birey kimi zaman da zorunlu bir eğitime tabi tutulmuştur. Türkiye'ye de benzer sebeplerle her yıl binlerce uluslararası öğrenci gelmektedir. Zorunlu göç, iş arayışı, nitelikli bir üniversitede eğitim alma isteği sebepleriyle ülkemize gelen öğrenciler için Türkçe öğrenme gereksinimi doğmaktadır. Bireylerin dil öğrenme süreçlerinde onları harekete geçirebilecek dürtüler gerekli görülmektedir. Dil öğrenme ilgi ve isteğinin, çok boyutlu bir kavram olan "güdülenme" sözcüğü ile ilişkisi vardır. "Güdülenme”, “motivasyon” sözcüğünün Türkçe karş1lığıdır. TDK'nin hazırladığı Türkçe Sözlük (2019: 1698) motivasyon sözcügünü, "isteklendirme, güdüleme" olarak tanımlanmaktadır. TÜBA Türkçe Bilim Terimleri Sözlüğü'nde $(2011,836)$ bu sözcük, "güdülenme" biçiminde tanımlanmıştır. Dil öğrenmede motivasyonun güçlü bir etkisi olduğu yapılan çalışmalarda aktarılmıştır. İkinci bir dil öğrenmenin önemini gösteren motivasyon kavramına yönelik çalışmalara ilgi yoğunlaşmıştır (Dörnyei, MacIntyre ve Henry, 2015; Emmanuel ve diğerleri, 2014; Nguyen, 2016).

Bireyi, dil öğrenme konusunda harekete geçiren motivasyon kavramı için farklı gruplandırmalar yapılmaktadır. Araştırmacılar genel olarak içsel ve dışsal motivasyon üzerinde durmaktadır. Bu çalışmada, içsel, araçsal ve kültürel motivasyon boyutları üzerinde durulacaktır. İçsel motivasyon, bir işi yapma isteği, zevk alarak yapma düşüncesi olarak değerlendirilebilir. Yeterli düzeyde güdülenmeye sahip olmak hedefleri gerçekleştirme noktasında etkili olmaktadır. Araçsal motivasyon, bir amaç doğrultusunda öğrenme olarak ele alınabilir. Öğrencilerin üniversitede eğitim alabilmek için ya da iş olanağı yakalayabilmek için Türkçe öğrenme çabası araçsal motivasyona örnek gösterilebilir. Kültürel motivasyon ise, dil öğrenen bireyin bulunduğu kültürel ortamdan etkilenmesi ya da dilin konuşulduğu ülkeye dair kültürel bir birikime sahip olması olarak adlandır1labilir.

Dil öğrenme sürecinde öğrenilen dilin konuşulduğu bir ülkede yaşamak motivasyon için belirleyici bir değişken olabilir. Bu bağlamda, Türkiye'de bulunan ve üniversitelerin Türkçe hazırlık bölümlerinde öğrenim gören uluslararası öğrencilerin motivasyon durumları belirlenmek istenmiştir. Araştırmanın amacı dikkate alınarak şu sorulara yanıt aranmıştır: 
1. Yabancı dil olarak Türkçe öğrenen uluslararası öğrencilerin motivasyon (içsel, araçsal ve kültürel) durumlarında ülkelerine göre anlamlı bir farklılık var midir?

2. Yabanc1 dil olarak Türkçe öğrenen uluslararası öğrencilerin motivasyon (içsel, araçsal ve kültürel) durumlarında yaşlarına göre anlamlı bir farklılık var midir?

3. Yabancı dil olarak Türkçe öğrenen uluslararası öğrencilerin motivasyon (içsel, araçsal ve kültürel) durumlarında dil seviyelerine (kur) göre anlamlı bir farklılık var midır?

\section{YÖNTEM}

\section{Araştırma Modeli}

Türkiye'de bulunan ve üniversitelerin Türkçe hazırlık bölümlerinde öğrenim gören uluslararası öğrencilerin motivasyon durumlarını belirleme nedeniyle yapılan bu çalışmada nicel araştırma yöntemlerinden biri olan tarama modeli kullanılmıştır. "Tarama, geçmişte ya da hâlen var olan bir durumu var olduğu gibi belirlemeyi amaçlayan, bireyi kendi koşulları içinde tanımlamaya çalışan bir modeldir" (Karasar, 2018: 109). Tarama araștırmasının faydası, oldukça fazla kişinin katılımını olanaklı kılarak elde edilen birçok bilgiyi sunmasıdır (Büyüköztürk, Kılıç, Akgün, Karadeniz, Demirel, 2018: 15).

\section{Çalışma Grubu}

Bu çalışmanın evrenini 2020-2021 yılları arasında Türkiye'de yaşayan, Ankara Medipol Üniversitesi ve Kahramanmaraş Sütçü İmam Üniversitesi Türkçe hazırlık kurslarında öğrenim görmekte olan, bunun yanı sıra Yedi Kıta Uluslararası Öğrenci Derneği'ne üye olup farklı üniversitelerin hazırlık kurslarında öğrenim görmekte olan farklı milletlerden öğrenciler oluşturmuştur. 103 öğrenci tesadüfi örneklem yoluyla seçilmiştir. Araştırmaya katılan uluslararası öğrencilere ilişkin özellikler Tablo 1'de yer almaktadır.

Tablo 1. Çalışma Grubuna İlişkin Özellikler

\begin{tabular}{llcc}
\hline & & $\mathrm{n}$ & $\%$ \\
\hline \multirow{3}{*}{ Ülke } & İran & 38 & 36,9 \\
& Endonezya & 36 & 35,0 \\
& Diğer & 29 & 28,2
\end{tabular}




\begin{tabular}{llll}
\hline \multirow{2}{*}{ Yaş 20 yaş altı } & 37 & 35,9 \\
& $20-24$ yaş & 48 & 46,6 \\
& 25 yaş ve üstü & 18 & 17,5 \\
\hline \multirow{3}{*}{ Kur (Seviye) } & B1 & 15 & 14,6 \\
& B2 & 56 & 54,4 \\
& C1 & 21 & 20,4 \\
& C2 & 11 & 10,7 \\
\hline
\end{tabular}

Tablo 1'e göre araştırmaya katılan ögrencilerin \%36.9'u İranlı, \%35'i Endonezyalı ve \%28.2'si diğer milletlerdendir ${ }^{2}$. Katılımcıların \%35.9'u 18-20, \%46.6'sı 20-24, \%17.5'i 25-35 yaş aralığındadır. Türkçe dil seviyelerine göre kat1lımciların 14.6's1 B1, 54.4'ü B2, 20.4'ü C1, 10.7'si C2 seviyesindedir.

\section{Veri Toplama Aracı}

Ölçek, Google Forms kullanılarak öğrencilere elektronik ortamda ulaştırılmıştır. Araştırmanın verileri Sevim (2019) tarafından geliştirilen, toplam üç boyuttan (içsel, araçsal ve kültürel) oluşan "Yabancı Dil Olarak Türkçe Öğrenmeye Yönelik Motivasyon" ölçeği ile toplanmıştır. Yabancı dil olarak Türkçe öğrenimi alanında motivasyona ilişkin ilk örnek olması ve üç farklı alt boyuttan oluşması sebebiyle önem taşımaktadır. Birinci boyutta bir araya gelen maddeler içsel motivasyon, ikinci boyuttaki maddeler araçsal motivasyon, üçüncü boyuttaki maddeler ise kültürel motivasyon adını almıştır.

İçsel motivasyon boyutunda 9, araçsal motivasyon boyutunda 8, kültürel motivasyon boyutunda ise 5 madde yer almaktadır. Ölçekte beşli Likert tipi (5=Tamamen katılıyorum, 4=Büyük ölçüde katıllyorum, 3=Kararsızım, 2=Çok az katılıyorum, 1=Hiç katılmıyorum) 22 madde bulunmaktadır. "Yabancı Dil Olarak Türkçe Öğrenmeye Yönelik Motivasyon Ölçeği’nin alt boyutlarının iç tutarlılık katsayılarının 0,84 ile 0,89 arasında değerler aldığı" belirlenmiştir (Sevim, 2019). Ölçeğin başına katılımcıların kişisel bilgilerine ulaşabilmek adına araştırmacı tarafından üç soru eklenmiş̧ir (Bk.: Ek 1). Öğrencilerin ülkelerini, yaşlarını ve dil seviyelerini öğrenmek amaçlanmıştır. Çalışmada ölçekte yer alan motivasyon durumlarına ait alt boyutlar dikkate alınmıştır. Alt boyutların

2 Diğer ülkeler; Somali, Suriye, Ukrayna, Cibuti, Fas, Yemen, Nepal, Afganistan, Bangladeş, Türkmenistan, Portekiz olarak belirlenmiştir. 
aritmetik ortalamaları ve standart sapmaları ile motivasyona yönelik sonuçlar tablo 2'de verilmiştir.

Tablo 2. Ölçeğin Alt Boyutlarına Ait Aritmetik Ortalamaları ve Standart Sapma Değerleri

\begin{tabular}{lccccc}
\hline & $\mathrm{n}$ & Minimum & Maksimum & Ort. & ss \\
\hline İçsel Motivasyon & 103 & 23,00 & 45,00 & 37,06 & 4,29 \\
Araçsal Motivasyon & 103 & 25,00 & 40,00 & 34,88 & 3,79 \\
Kültürel Motivasyon & 103 & 8,00 & 25,00 & 19,50 & 3,91 \\
$\begin{array}{l}\text { Yabancı Dil Olarak Türkçe Öğrenmeye } \\
\text { Yönelik Motivasyon }\end{array}$ & 103 & 61,00 & 110,00 & 91,45 & 9,02 \\
\hline
\end{tabular}

\section{Verilerin Analizi}

Araştırmada "Yabancı Dil Olarak Türkçe Öğrenmeye Yönelik Motivasyon Ölçeği” "nden elde edilen veriler, SPSS 24.0 ile analiz edilmiştir. Çalışmada ölçek bilgisine göre ölçek puanları belirlenmiş ve puanların normal dağılıma uygunluğunun ortaya konulabilmesi için basıklık ve çarpıklık katsayıları incelenmiştir. Ölçekten elde edilen basıklık ve çarpıklık değerlerinin +3 ile -3 arasında çıkmasının normal dağılım için yeterli görüldüğü söylenebilir. (Groeneveld ve Meeden, 1984; Moors, 1986; Hopkins ve Weeks, 1990; De Carlo, 1997).

Tablo 3. Puanların Basıklık ve Çarpıklık Katsayıları

\begin{tabular}{lccc}
\hline & $\mathrm{n}$ & Çarpıklık & Basıklık \\
\hline İçsel Motivasyon & 103 & $-0,517$ & 0,356 \\
Araçsal Motivasyon & 103 & $-0,470$ & $-0,494$ \\
Kültürel Motivasyon & 103 & $-0,837$ & 0,358 \\
Yabancı Dil Olarak Türkçe Öğrenmeye Yönelik & 103 & $-0,365$ & 0,272 \\
Motivasyon & & & \\
\hline
\end{tabular}

Puanlar incelendiğinde tüm puanların basıklık ve çarpıklık katsayıları -3 ile +3 arasında çıkmıştır. Buna göre, puanların normal dağılım gösterdiği belirlenmiştir. Puanlar normal dağılım gösterdiği için çalışma sürecinde parametrik test teknikleri kullanılmıştır. Ölçekten elde edilen puanların 
demografik özelliklere göre nasıl farklılık gösterdiğini belirlemek için $t$ testi ve ANOVA testi kullanılmıştır. T testi, 2 gruplu demografik değişkenlerin değerlendirilmesinde kullanılırken ANOVA testi $\mathrm{k}(\mathrm{k}>2)$ gruplu değişkenlerin analizinde kullanılmıştır.

\section{BULGULAR}

\section{Birinci Alt Amaca İlişkin Bulgular}

Araştırmanın birinci alt amacı olan "Yabancı dil olarak Türkçe öğrenen uluslararası öğrencilerin motivasyon (içsel, araçsal ve kültürel) durumlarında ülkelerine göre anlamlı bir farklılık var mıdır?” sorusuna ilişkin bulgular şu şekildedir:

Tablo 4. Yabancı Dil Olarak Türkçe Öğrenmeye Yönelik Motivasyonun Ülke Açısından İncelenmesi

\begin{tabular}{llccccc}
\hline & & n & Ort. & ss & F & p \\
\hline İçsel Motivasyon & İran & 38 & 36,74 & 3,45 & & \\
& Endonezya & 36 & 36,69 & 4,98 & $\mathbf{0 , 8 3 4}$ & $\mathbf{0 , 4 3 7}$ \\
& Diğer & 29 & 37,93 & 4,37 & & \\
\hline & İran & 38 & 35,79 & 3,66 & & \\
Araçsal Motivasyon & Endonezya & 36 & 35,19 & 3,25 & $\mathbf{3 , 9 1 3}$ & $\mathbf{0 , 0 2 3}$ \\
& Diğer & 29 & 33,31 & 4,20 & & \\
\hline & İran & 38 & 20,03 & 3,75 & & \\
Kültürel Motivasyon & Endonezya & 36 & 19,44 & 3,52 & $\mathbf{0 , 6 8 9}$ & $\mathbf{0 , 5 0 5}$ \\
& Diğer & 29 & 18,90 & 4,56 & & \\
\hline \multirow{2}{*}{$\begin{array}{l}\text { Yabancı Dil Olarak } \\
\text { Yürkce Ö̈ğrenmeye }\end{array}$} & İran & 38 & 92,55 & 8,30 & & \\
\hline & Endonezya & 36 & 91,33 & 9,20 & $\mathbf{0 , 5 8 9}$ & $\mathbf{0 , 5 5 7}$ \\
& Diğer & 29 & 90,14 & 9,82 & & \\
\hline
\end{tabular}

${ }_{* \mathbf{p}}<\mathbf{0 , 0 5}$

Yabancı Dil Olarak Türkçe Öğrenmeye Yönelik Motivasyonun ülke açısından incelenmesi amaciyla yapılan ANOVA testi sonuçları tablo 4'te verilmiştir. Analiz sonuçlarına göre Araçsal Motivasyon, ülkeye göre anlamlı farkl1lık göstermektedir $(p<0,05)$ ve İranlı öğrencilerin Araçsal Motivasyon puanları en yüksektir. İçsel Motivasyon, Kültürel Motivasyon ve Yabancı Dil Olarak Türkçe Öğrenmeye Yönelik Motivasyon, ülkeye göre anlamlı farkl1lık göstermemektedir 
( $p>0,05)$. Araçsal motivasyon kavramın, bireyin dili kullanma amacı (iş bulma konusunda başarısız olma korkusu, daha iyi bir kazanç elde etme, yüksek puan alma, bir ülkede yaşama şansının devamlılığı) doğrultusunda öğrenmesi olarak ele alınabilir. Son yıllarda İranlı öğrencilerin Türkiye'de eğitim almak amacıyla Türkiye'ye yerleşme isteği artmıştır. Sonuçlara bakıldığında, ülkelere göre kültürel motivasyon puan ortalamalarının düşük olduğu dikkat çekmektedir. Bu durum İranlı ögrencilerin amaca yönelik dil öğrenimi gerçekleştirdiklerini açıklar niteliktedir.

\section{İkinci Alt Amaca İlişkin Bulgular}

Araştırmanın ikinci alt amacı olan "Yabancı dil olarak Türkçe öğrenen uluslararası öğrencilerin motivasyon (içsel, araçsal ve kültürel) durumlarında yaşlarına göre anlamlı bir farklılık var mıdır?" sorusuna ilişkin bulgular şu şekildedir:

Tablo 5. Yabancı Dil Olarak Türkçe Öğrenmeye Yönelik Motivasyonun Yaş Açısından İncelenmesi

\begin{tabular}{|c|c|c|c|c|c|c|}
\hline & & $\mathbf{n}$ & Ort. & ss & $\mathbf{F}$ & $\mathbf{p}$ \\
\hline \multirow{3}{*}{ İçsel Motivasyon } & 20 yaş altı & 37 & 36,38 & 4,80 & \multirow{3}{*}{1,582} & \multirow{3}{*}{0,211} \\
\hline & 20-24 yaş & 48 & 37,02 & 4,21 & & \\
\hline & 25 yaş ve üstü & 18 & 38,56 & 2,99 & & \\
\hline \multirow{3}{*}{ Araçsal Motivasyon } & 20 yaş altı & 37 & 35,27 & 3,83 & \multirow{3}{*}{0,299} & \multirow{3}{*}{0,742} \\
\hline & 20-24 yaş & 48 & 34,69 & 3,90 & & \\
\hline & 25 yaş ve üstü & 18 & 34,61 & 3,55 & & \\
\hline \multirow{3}{*}{ Kültürel Motivasyon } & 20 yaş altı & 37 & 19,49 & 3,63 & \multirow{3}{*}{0,314} & \multirow{3}{*}{0,731} \\
\hline & $20-24$ yaş & 48 & 19,75 & 3,56 & & \\
\hline & 25 yaş ve üstü & 18 & 18,89 & 5,31 & & \\
\hline \multirow{3}{*}{$\begin{array}{l}\text { Yabancı Dil Olarak } \\
\text { Türkçe Öğrenmeye } \\
\text { Yönelik Motivasyon }\end{array}$} & 20 yaş altı & 37 & 91,14 & 9,53 & \multirow{3}{*}{0,062} & \multirow{3}{*}{0,940} \\
\hline & 20-24 yaş & 48 & 91,46 & 8,87 & & \\
\hline & 25 yaş ve üstü & 18 & 92,06 & 8,83 & & \\
\hline
\end{tabular}

Yabancı Dil Olarak Türkçe Öğrenmeye Yönelik Motivasyonun yaş açısından incelenmesi amacıyla yapılan ANOVA testi sonuçları tablo 5'te verilmiştir. 
Analiz sonuçlarına göre İçsel Motivasyon, Araçsal Motivasyon, Kültürel Motivasyon ve Yabancı Dil Olarak Türkçe Öğrenmeye Yönelik Motivasyon, yaşa göre anlamlı farkl1lık göstermemektedir $(p>0,05)$. Buna göre Türkçeyi yabanc1 dil olarak öğrenen öğrencilerin yaşları, onların Türkçe öğrenme motivasyonlarına istatistikî olarak etki etmemektedir.

\section{Üçüncü Alt Amaca İlişkin Bulgular}

Araştırmanın üçüncü alt amacı olan "Yabancı dil olarak Türkçe öğrenen uluslararası öğrencilerin motivasyon (içsel, araçsal ve kültürel) durumlarında dil seviyelerine göre anlamlı bir farklılık var mıdır?" sorusuna ilişkin bulgular şu şekildedir:

Tablo 6. Yabancı Dil Olarak Türkçe Öğrenmeye Yönelik Motivasyonun Kur (Seviye) Açısından İncelenmesi

\begin{tabular}{|c|c|c|c|c|c|c|}
\hline & & $\mathbf{n}$ & Ort. & ss & $\mathbf{F}$ & $\mathbf{p}$ \\
\hline \multirow{4}{*}{ İçsel Motivasyon } & B1 & 15 & 36,87 & 5,32 & \multirow{4}{*}{0,445} & \multirow{4}{*}{0,721} \\
\hline & B2 & 56 & 36,70 & 4,62 & & \\
\hline & $\mathrm{C} 1$ & 21 & 37,86 & 3,32 & & \\
\hline & $\mathrm{C} 2$ & 11 & 37,64 & 2,42 & & \\
\hline \multirow{4}{*}{ Araçsal Motivasyon } & B1 & 15 & 34,47 & 3,85 & \multirow{4}{*}{1,635} & \multirow{4}{*}{0,186} \\
\hline & B2 & 56 & 34,36 & 3,97 & & \\
\hline & $\mathrm{C} 1$ & 21 & 35,57 & 3,70 & & \\
\hline & $\mathrm{C} 2$ & 11 & 36,82 & 2,27 & & \\
\hline \multirow{4}{*}{ Kültürel Motivasyon } & B1 & 15 & 19,93 & 3,39 & \multirow{4}{*}{1,224} & \multirow{4}{*}{0,305} \\
\hline & B2 & 56 & 19,45 & 4,03 & & \\
\hline & $\mathrm{C} 1$ & 21 & 20,33 & 2,56 & & \\
\hline & $\mathrm{C} 2$ & 11 & 17,64 & 5,64 & & \\
\hline \multirow{4}{*}{$\begin{array}{l}\text { Yabancı Dil Olarak } \\
\text { Türkçe Öğrenmeye } \\
\text { Yönelik Motivasyon }\end{array}$} & B1 & 15 & 91,27 & 8,92 & \multirow{4}{*}{0,681} & \multirow{4}{*}{0,566} \\
\hline & B2 & 56 & 90,50 & 9,72 & & \\
\hline & C1 & 21 & 93,76 & 7,06 & & \\
\hline & C2 & 11 & 92,09 & 9,12 & & \\
\hline
\end{tabular}


Yabanc1 Dil Olarak Türkçe Öğrenmeye Yönelik Motivasyonun kur (seviye) açısından incelenmesi amacıyla yapılan ANOVA testi sonuçları tablo 6'da verilmiştir. Analiz sonuçlarına göre İçsel Motivasyon, Araçsal Motivasyon, Kültürel Motivasyon ve Yabancı Dil Olarak Türkçe Öğrenmeye Yönelik Motivasyon, dil seviyelerine göre anlamlı farkl1lı göstermemektedir ( $\mathrm{p}>0,05)$. Buna göre Türkçeyi yabancı dil olarak öğrenen öğrencilerin orta (B1-B2) ya da üst (C1-C2) kurlarda olmaları, onların Türkçe öğrenme motivasyonlarına istatistikî olarak etki etmemektedir.

\section{SONUÇ VE TARTIŞMA}

Yapılan bu araştırmayla yabancı dil olarak Türkçe öğrenen öğrencilerin motivasyon durumları belirlenmeye çalışılmış ve bunun yanı sıra Türkçe öğrenme motivasyonları çeşitli değişkenler açısından değerlendirilmiştir.

Çalışmanın verileri değerlendirildiğinde, yabancı dil olarak Türkçe öğrenen öğrencilerin araçsal motivasyon puanları, ülkeye göre anlamlı farklılık göstermektedir $(\mathrm{p}<0,05)$ ve İranlı öğrencilerin araçsal motivasyon puanlarının yüksek olduğu belirlenmiştir. Ryan ve Deci'ye (2000, s. 60) göre, dişsal motivasyon "Aktiviteyi birtakım farkedilebilir sonuçlara ulaşmak için yapmaktır." İranlı öğrencilerin, öğrenme konusundaki içsel arzuyu dinlemek yerine belirli bir işe odaklanarak amaca yönelik dil öğrendikleri söylenebilir. Öğrenciler koşullu hedeflere hızla erişebilmek adına dil öğrenme motivasyonlarını yüksek tutmaktadırlar. Yabancı dil olarak Türkçe öğrenen İranlı öğrencilerin kendilerini motive etme yöntemleri; iyi bir iş olanağı bulabilme, Türkiye'de yaşamını devam ettirebilme ve daha iyi Türkçe konuşarak Türklerle iletişimi güçlendirebilme isteği olarak ele alınabilir. Tüm bunlar bir amaç doğrultusunda dil öğrenildiğini gösterir. Alan yazındaki çalışmalarda da benzer sonuçlar elde edilmiştir. Tok ve Yığın'ın (2013) yaptığı araştırma sonuçlarına göre, uluslararası öğrencilerin öncelikle ekonomik ve eğitim amacıyla Türkçeyi öğrenmek istedikleri görülmüştür. Kuşçu'nun (2014) araştırmasında da yabancı dil olarak Türkçe öğrenen öğrencilerin iyi iş olanakları ile karşılaşacaklarına ve ana dili Türkçe olan bireylerle iletişimlerinin güçleneceğine inandıkları belirtilmiştir.

Yabancı dil olarak Türkçe öğrenen öğrencilerin içsel ve kültürel motivasyonları ülke, yaş, kur düzeyi değişkenlerine göre istatistikî olarak anlamlı bir farklılık oluşturmamıştır. Öğrencilerin tüm ölçekten elde ettikleri puanlara bakıldığında, dil öğrenme motivasyonlarının ülkeye, yaşa ve dil seviyesine göre yüksek olduğu söylenebilir. Brown (2000: 181), "Öğrencilerin hedef dil ve kültüre olan tutumlarının dil öğrenme sırasındaki başarıyı etkilediğine vurgu yapmaktadır. $\mathrm{Bu}$ nedenle öğreticinin olumlu veya olumsuz tutumlara karşı 
dikkatli davranarak hedef dilin konuşulduğu sosyal ve kültürel yapı hakkında da bilgi sunması gerekmektedir" (Byram vd. 2002: 4). Ancak tüm alt boyutlara göre kültürel motivasyon puan ortalamaları düşük çıkmıştır. "Kültürel arka plandan yoksun bir dil öğretimin birtakım eksikleri barındıracağı fikri ortaya çıkmaktadır" (Brown, 2000: 189). Elde edilen bu sonuçlara göre, öğrencilerin içsel ve kültürel motivasyon düzeylerini arttırmaya yönelik öğretim sürecinde çeşitli etkinlikler oluşturulması gerektiği söylenebilir.

\section{KAYNAKÇA}

Brown, H. Douglas (2000). Principles of Language Learning and Teaching, Longman.

Büyüköztürk Ş., Kılıç Çakmak E., Akgün Ö. E., Karadeniz Ş., Demirel F. (2018). Bilimsel Araştırma Yöntemleri. Pegem Akademi.

Byram, Michael, Gribkova, Bella and Starkey, Hugh (2002). Developing The Intercultural Dimension in Language Teaching A Practical Introduction For Teachers, Council of Europe.

De Carlo, L.T. (1997), On the Meaning and Use of Kurtosis, Psychological Methods, 2: 292-307.

Dörnyei. Z., MacIntyre, P., and Henry, A. (Eds.) (2015). Motivational Dynamics in Language Learning. Multilingual Matters.

Emmanuel, A. O., Adom, E. A., Josephine, B. and Solomon, F. K. (2014). Achievement Motivation, Academic Self-Concept and Academic Achievement Among High School Students. European Journal of Research and Reflection in Educational Sciences, 2(2), 24-34.

Groeneveld, R.A. and Meeden, G. (1984), "Measuring Skewness and Kurtosis”, The Statistician, 33: 391-399.

Hopkins, K.D. and Weeks, D.L. (1990), Tests for Normality and Measures of Skewness and Kurtosis: Their Place in Research Reporting, Educational and Psychological Measurement, 50: 717-729.

Kuşçu, S. (2014). Türkçenin Yabancı Dil Olarak Öğretiminde Öğretmen Bilişi ve Öğrenci İnanışları. Hacettepe Üniversitesi Yabancı Dil Olarak Türkçe Araştırmaları Dergisi, 1, 111-120.

Moors, J. J. A. (1986), The Meaning of Kurtosis: Darlington Reexamined, The American Statistician, 40: 283-284. 
Nguyen N. (2016). Motivation in Language Learning and Dörnyei's L2 Motivational Self System. In: Liyanage I., Nima B. (Ed.) Multidisciplinary Research Perspectives in Education. SensePublishers. https://doi.org/10.1007/978-94-6300-615-6_9

Ryan, R. M., and ve Deci, E. L. (2000). Intrinsic and Extrinsic Motivations: Classic Definitions and New Directions. Contemporary Educational Psychology, 25(1), 54-67.

Sevim, O. (2019). Yabancı Dil Olarak Türkçe Öğrenmeye Yönelik Motivasyon: Bir Ölçek Geliştirme Çalışması. Türkiyat Araştırmaları Enstitüsü Dergisi. TAED, 65, 567-586.

TDK (2019). Türkçe Sözlük. Türk Dil Kurumu Yayınları.

Tok, M. ve Yıgın, M. (2013). Yabancı Uyruklu Öğrencilerin Türkçe Öğrenme Nedenlerine İlişkin Bir Durum Çalışması. Dil ve Edebiyat Eğitimi Dergisi, 8, 132-147.

TÜBA (2011). Türkçe Bilim Terimleri Sözlüğ̈̈ Sosyal Bilimler. TÜBA Yayını.

Yayla, M. (2018). Yabancı Dil Olarak Türkçe Öğrenenlerde İdeal İkinci Dil (D2) Benliği ve İletişim Kurma İstekliliği, [Yüksek Lisans Tezi], Hacettepe Üniversitesi. 